\title{
Homologies of the Anterior Teeth in Indriidae and a Functional Basis for Dental Reduction in Primates
}

\author{
PHILIP D. GINGERICH \\ Museum of Paleontology, The University of Michigan, Ann Arbor, Michigan 48109
}

\begin{abstract}
KEY WORDS Dental reduction . Lemuriform primates . Indriidae . Dental homologies . Dental scraper . Deciduous dentition - Avahi
\end{abstract}

\begin{abstract}
In a recent paper Schwartz ('74) proposes revised homologies of the deciduous and permanent teeth in living lemuriform primates of the family Indriidae. However, new evidence provided by the deciduous dentition of $A v a h i$ suggests that the traditional interpretations are correct, specifically: (1) the lateral teeth in the dental scraper of Indriidae are homologous with the incisors of Lemuridae and Lorisidae, not the canines; (2) the dental formula for the lower deciduous teeth of indriids is 2.1.3; (3) the dental formula for the lower permanent teeth of indriids is 2.0.2.3; and (4) decrease in number of incisors during primate evolution was usually in the sequence I3, then I2, then I1. It appears that dental reduction during primate evolution occurred at the ends of integrated incisor and cheek tooth units to minimize disruption of their functional integrity.
\end{abstract}

Anterior dental reduction in the primate family Indriidae illustrates a more general problem of direction of tooth loss in primate evolution. All living lemuroid and lorisoid primates (except the highly specialized Daubentonia) share a distinctive procumbent, comblike configuration of the anterior lower dentition - the dental scraper or "toothcomb" used in ingesting resin, prying bark, and in grooming. This dental scraper is composed of six teeth in Lemuridae and Lorisidae, generally considered to be four incisors bordered by two canines (Swindler, '76). The dental scraper of Indriidae consists of only four teeth. It is agreed that these teeth are homologous with four of the six teeth in the scraper of lemurids and lorisids, but the question remains whether the two teeth lost in going from the generalized lemurid condition to the more specialized indriid condition were incisors or canines. The four teeth remaining in the dental scraper of Indriidae are usually considered to be incisors (i.e., the canines were lost; see Vallois, '55; Le Gros Clark, '71; Martin, '72; among others), but they have also been interpreted as an incisor pair bordered by left and right lower canine teeth (i.e., an incisor pair was lost: e.g., Gregory, '20: p. 214).
Schwartz (74) recently reviewed the problem of tooth homologies in the dental scraper of Indriidae and concluded that no real evidence has ever been presented to support the interpretation that indriids possess four lower incisors and no canines. He then gave several reasons in support of the contrary interpretation that two incisors and two canines make up the indriid scraper.

In the course of a study of dental variation in Indriidae, a specimen of Avahi retaining deciduous teeth was found that supports the traditional interpretation of homologies of the permanent and deciduous dentition of Indriidae. This new evidence is presented to help clarify anterior dental reduction in Indriidae. The whole problem is especially important as it has a direct bearing on our understanding of the general problem of dental reduction in primate evolution.

\section{MATERIALS AND RESULTS}

Dried skulls of adult animals of virtually all genera of Lemuridae, Lorisidae, and Indriidae were examined in the collections of the Cleveland Museum of Natural History, the British Museum (Natural History) in London, the Rijksmuseum van Natuurlijke Historie in Leiden, and the Laboratoire d'Anatomie Com- 
paree in Paris. In addition, I studied the deciduous dentition in various stages of replacement in many of these genera. The deciduous dentitions of representative Indriidae and Lemuridae are illustrated in plate 1.

Lemuridae, Lorisidae, and Indriidae have the same number of deciduous teeth (six) in each mandible. These teeth in Lorisidae and Lemuridae (figs. 3,4 ) have basically the same morphology, and the deciduous formula is agreed to be 2.1.3, with the first three teeth forming a deciduous dental scraper. In the Indriidae, both Indri and Propithecus (fig. 1) have a rather different configuration, with only two procumbent anterior teeth in each mandible contributing to the deciduous dental scraper. In Indri and Propithecus these are followed by a small tooth, a relatively large tooth, a small tooth, and another relatively large tooth. By comparison with Lemuridae, the deciduous dental formula of Indriidae is usually given as 2.1.3 in spite of the morphological differences of the teeth from those in Lemuridae. However, Schwartz ('74) has recently interpreted this deciduous formula as 1.1.4 (as did Gregory, '20).

The smallest indriid species, Avahi laniger, significantly has an anterior deciduous dentition more similar to that of Lemuridae than to Indri and Propithecus (fig. 2). Of particular importance is the third tooth in the deciduous series, a tooth Schwartz (74) called tooth "A." Tooth "A" in Indri and Propithecus (fig. 1) is a very small tooth usually separated from the dental scraper by a small diastema. However, in Avahi this tooth "A" has an elongated, procumbent crown that forms a functional unit with the other teeth of the deciduous dental scraper. The crown of tooth "A" in Avahi is relatively much larger than tooth "A" in Indri and Propithecus. It does not show the wear found in Schwartz's Age Group II Indriidae and its position cannot be attributed to mesial drift associated with wear. Because of its similarity in position and morphology to the lower deciduous canine of Lemuridae, tooth "A" in Avahi is almost certainly a deciduous canine as well. Since the remaining teeth in the deciduous dentition of Avahi are very similar to those of Propithecus and Indri, it is difficult to avoid the conclusion that the reduced tooth " $\mathrm{A}$ " in the latter two genera is homologous with tooth "A" in Avahi. Thus, in spite of the reduced size of tooth " $A$ " in Indri and Propithecus compared to the deciduous canine of Lemuridae, tooth " $\mathrm{A}$ " in Indriidae is almost certainly a deciduous canine. The lower deciduous formula of the Indriidae is thus probably 2.1.3 as it is in Lemuridae and Lorisidae, which also matches the upper deciduous formula in these three families.

As shown in figures 3 and 4 , the incisors and canines of the deciduous dental scraper in Lemuridae are all replaced by incisors and canines of the permanent scraper, whereas in Propithecus, Indri, and Avahi (fig. 2), the de ciduous canine " $A$ " is not replaced by a permanent tooth. Thus it appears that the permanent lower dental formula of Indriidae is properly interpreted as 2.0 .2 .3 , which matches the permanent upper formula of 2.1.2.3 except for loss of the canine.

\section{DISCUSSION OF HOMOLOGIES IN INDRIIDAE}

Schwartz ('74) based his conclusion that the lower deciduous dental formula of Indriidae is 1.1.4 and the lower permanent formula 1.1.2.3 on three lines of evidence: (1) the morphology of the lateral tooth in the indriid dental scraper (both deciduous and permanent) is most similar to that of the canine in lemurids and lorisids; (2) tooth " $A$ " in indriids sometimes occludes behind the upper canine and thus by definition tooth " $A$ " must be a deciduous premolar and not a canine; and (3) ontogenetic studies on the mammalian dentition have shown that incisor teeth develop from the dental lamina in an anteroposterior direction. Each of these lines of evidence is discussed in turn.

Dental morphology is correlated with tooth function, and morphological similarity is not always a reliable indicator of homology. The left and right lateral teeth in the indriid dental scraper are most similar morphologically to the canines in the lemurid or lorisid dental scraper. The main feature that makes them similar is a raised crest running along the lateral margin from the tip to the base of the crown. However, a very similar raised lateral crest (a "margocristid": Gingerich, '76) is also present on the enlarged procumbent central incisors of early Tertiary plesiadapid, microsyopid, and omomyid primates. Further more, a 6-tooth dental scraper or comb virtually identical to that of a lemur, including the raised margocristids on the lateral teeth, is known in the early Eocene condylarth Thryptacodon (Princeton University no. 20853), which also retains large projecting canine teeth - the lemur-like lateral teeth of 
the scraper are thus incisors and not canines as in Lemur. The presence of raised margocristids on the lateral teeth in the dental scraper of indriids is probably closely correlated with tooth position and dental function and not a reliable indicator of their homology with the lower canines of lemurids.

The fact that tooth " $\mathrm{A}$ " sometimes occludes behind the deciduous upper canine (in very young individuals of Schwartz's Age Group I) does not necessarily define its homology, as Schwartz (74: p. 112) suggests. The conventional identifications of teeth widely used in mammalogy refer primarily to tooth positions and occlusal relationships in primitive and generalized mammals - to prove that a given tooth in a specialized mammal is homologous with the canine tooth in a generalized mam. mal requires that the tooth be traced phyletically back to the canine in a generalized mammal. Unfortunately, the fossil record of Indriidae is insufficient to permit one to trace the deciduous tooth "A" back to its homologue in a generalized mammal - it can only be compared with similar teeth occupying the same position in the closely related Lemuridae and Lorisidae. As discussed above, when the deciduous dentition of Avahi is compared with that of the Lemuridae, it is seen that tooth " $A$ " in Indriidae is almost certainly homologous with the tooth identified in Lemuridae as a deciduous lower canine and not a premolar.

Phylogenetic sequences are not necessarily recapitulated in ontogenetic sequences, and ontogenetic development cannot be used in any deterministic way to rediscover phylogenetic history. Functional adaptation and the selective value of all stages of development prevent a direct reading of phylogenetic history from ontogenetic sequences. Thus one must view cautiously Schwartz's ('74) suggestion that incisors will be lost phylogenetically from the front to the back of the jaws because they develop ontogenetically from the front to the back. Schwartz's discussion ('74: pp. 112113) is based on the questionable assumption that the development of the incisor series plays an essential role in development of the canine. According to Schwartz, inhibition of the posterior end of the incisor sequence would effect an inhibition on the canine. To prevent this inhibition of canine development, Schwartz reasons that incisor inhibition would occur at the front and not at the back of the incisor series. However, the reference
Schwartz cites on dental development in mammals, Osborn ('73: p. 554) states that incisor, canine, and molar determinants are usually present in the earliest embryos in which tooth formation is evident. In other words, the canine determinant is present whether the incisor developmental sequence approaches it or not. Thus it is unlikely that Schwartz is correct in assuming that inhibition of the posterior incisor series would effect an inhibition of the canine. Following Osborn ('73), the fact that deciduous incisors develop from front to back would make it appear that the easiest way to reduce the number of incisors in a dental series would be to suppress those that develop last, i.e., reduce the sequence by losing $I_{3}$ first, then $I_{2}$, and finally $\mathbf{I}_{1}$.

\section{FUNCTIONAL BASIS FOR DENTAL REDUCTION IN PRIMATES}

Another reason to expect incisors to be lost from back to front has to do with the functional adaptation interface between development and phylogeny alluded to above. The mammalian dentition can be divided into several functional units: an incisor unit related to food acquisition; a canine unit related to food acquisition, display, etc.; and a cheek tooth unit related to the mastication of food. These functional units obviously correspond to Butler's ('39) morphogenetic fields in the mammalian dentition. If any unit is reduced in functional importance it may be reduced in size, and perhaps ultimately lost. This gradual reduction can be expected to proceed in a definite way, however, to preserve the functional integrity of the unit as a whole. If projecting and interlocking canine teeth are not required they can be reduced and altered into incisiform or premolariform teeth to contribute to food acquisition or mastication. In some mammals the canines are lost entirely.

Since the cheek tooth series usually functions as a unit in each jaw, loss of teeth from the front or back of the series would be expected rather than loss of teeth from the middle of the series. An exception may occur when the most anterior lower premolar participates in the canine functional unit (as happens in Indriidae, where $P_{3}$ appears to have been lost, while $P_{2}$ was retained as part of the canine unit; see fig. 1 and Godfrey, '76). Loss of $\mathrm{M}_{3}$ in New World Callitrichidae illustrates molar loss from the back of the cheek tooth series. 
Given that left and right incisors function as a single unit crossing the midline of the skull, one would expect, for functional reasons, that loss of incisors would occur from the sides of the unit and not from the middle of it. This is perhaps the most compelling reason why one would expect that incisors would be lost in the sequence $I_{3}$, then $I_{2}$, and finally $I_{1}$. In lemuriform primates where the lower canines are functionally the lateral members of the incisor series, one would expect the canines to be lost before the more centrally placed incisors are, and this sequence appears to be documented by partial reduction of the lower deciduous canines in Avahi, their more complete reduction in Propithecus and Indri, and complete loss of lower canines in the permanent dentition of all three extant genera of Indriidae.

In some of the best documented phyletic series of fossil primates, incisors were clearly lost from back to front (Plesiadapidae: Gingerich, '76), and premolars of the cheek tooth series were reduced from front to back (Plesiadapidae, Carpolestidae: Rose, '75; Adapidae: Gingerich, '77).

For reasons primarily related to the functional integrity of the incisor and cheek tooth units, it is concluded that incisors are usually lost phylogenetically from back to front in primates (i.e. in the sequence $I_{3}$, then $I_{2}$, then $I_{1}$ ), premolars are usually lost from front to back, and molars are usually lost from back to front. This general conclusion makes sense developmentally in that it is easily effected by suppression of the latest forming tooth buds, and it is supported by the available paleontological evidence.

\section{ACKNOWLEDGMENTS}

I thank Doctors P. Napier, British Museum (Natural History) in London; F. K. Jouffroy and J. Lessertisseur, Laboratoire d'Anatomie Comparée in Paris; L. B. Holthuis, Rijks- museum van Natuurlijke Historie in Leiden; and P. Helwig, Cleveland Museum of Natural History in Cleveland for access to specimens on which this study is based. I thank David C. Parris, Princeton University, for permission to cite the presence of a lemur-like dental scraper in a specimen of Thryptacodon that he is currently studying. In addition, I thank Karna Steelquist for printing the photographs for the plate, and Mrs. Gladys Newton for typing the manuscript. Travel funds for this study were provided by a Scott Turner Award in Earth Sciences through the Department of Geology and Mineralogy, The University of Michigan. Comments by two anonymous reviewers improved the manuscript.

\section{LITERATURE CITED}

Butler, P. M. 1939 Studies of the mammalian dentition - differentiation of the post-canine dentition. Proc. Zool Soc. Lond., 109 (B): 1-36.

Gingerich, P.D. 1976 Cranial anatomy and evolution of early Tertiary Plesiadapidae (Mammalia, Primates). University Michigan Papers Paleontology, 15: 1-140.

Gingerich, P. D. 1977 Radiation of Eocene Adapidae in Europe. Geobios, in press.

Godfrey, L. 1976 Dental reduction in the Indriidae. In: The Measures of Man. E. Giles and J. S. Friedlander, eds. Peabody Museum Press, Harvard University, Cambridge, Massachusetts.

Gregory, W. K. 1920 On the structure and relations of Notharctus, an American Eocene primate. Mem. Amer. Mus. Nat. Hist. (N. S.), 3: 49-243.

Le Gros Clark, W. E. 1971 The Antecedents of Man. Third ed. Quadrangle Books, Chicago.

Martin, R. D. 1972 Adaptive radiation and behaviour of the Malagasy lemurs. Phil. Trans. Roy. Soc. Lond., 264 (B): 295-352.

Osborn, J. W. 1973 The evolution of dentitions. Am. Scientist, 61: 548-559.

Rose, K. D. 1975 The Carpolestidae, early Tertiary primates from North America. Bull Mus. Comp. Zool., 147: 1.74.

Schwartz, J. H. 1974 Observations on the dentition of the Indriidae. Am. J. Phys. Anthrop., 41: 107-114.

Swindler, D. S. 1976 Dentition of Living Primates. Academic Press, New York.

Vallois, H. 1955 Ordre des primates. In: Traite de Zoologie, P.-P. Grassé, ed. Masson, Paris, v. 17, pp. 1854-2206. 
PLATE 
PLATE 1

EXPLANATION OF FIGURES

1 Propithecus verreauxi in oblique lateral view, showing the deciduous dentition. Permanent first and second molars in course of eruption are visible in the upper dentition. Tooth " $A$ " is here regarded as the deciduous lower canine by analogy with tooth " $\mathrm{A}$ " in Avohi (fig. 2) and the deciduous lower canine of Hapalemur (C in fig. 3) and Lemur (C in fig. 4). Scale approximately twice natural size. Specimen is in Leiden, Propithecus verr. coquereli "f."

2 Avahi laniger in occlusal view stereophotograph, showing the lower deciduous dentition. Deciduous $\mathrm{P}_{4}$ has been replaced by the erupting permanent $P_{4}$, and $M_{1}$ is fully erupted. Tooth " $A$ " is followed by $d P_{2}$ and a small $\mathrm{dP}_{3}$ on the left side, as in Propithecus (fig. 1). On the right side $\mathrm{dP}_{3}$ has fallen out. Note the forwardly inclined, styliform tooth $A$, which is slightly reduced in size but otherwise similar to the deciduous canine (C) in Hapalemur (fig. 3) and Lemur (fig. 4). The central four teeth are permanent replacement teeth, but tooth " $A$ " lacks a permanent replacement. Scale four times natural size. Specimen is in Leiden, no. 23118.

3 Hapalemur griseus in occlusal view stereophotograph showing the lower deciduous dentition and the lower first permanent molar. Tooth " $\mathrm{C}$," the lateral tooth in the deciduous dental scraper is replaced by the permanent canine, which also forms the lateral tooth in the permanent dental scraper. Scale is twice natural size. Specimen is in Leiden, Hapalemur griseus "p."

4 Lemur macaco in occlusal view stereophotograph showing the lower deciduous dentition and the lower first permanent molar. As in Hapalemur (fig. 3), tooth " $\mathrm{C}$ " is the deciduous lower canine. Note six teeth of the permanent dental scraper visible behind the teeth formig the deciduous scraper. Scale is twice natural size. Specimen is in Leiden, Lemur macaco "w." 
DENTAL REDUCTION IN PRIMATES

Philip D. Gingerich

PLATE 1
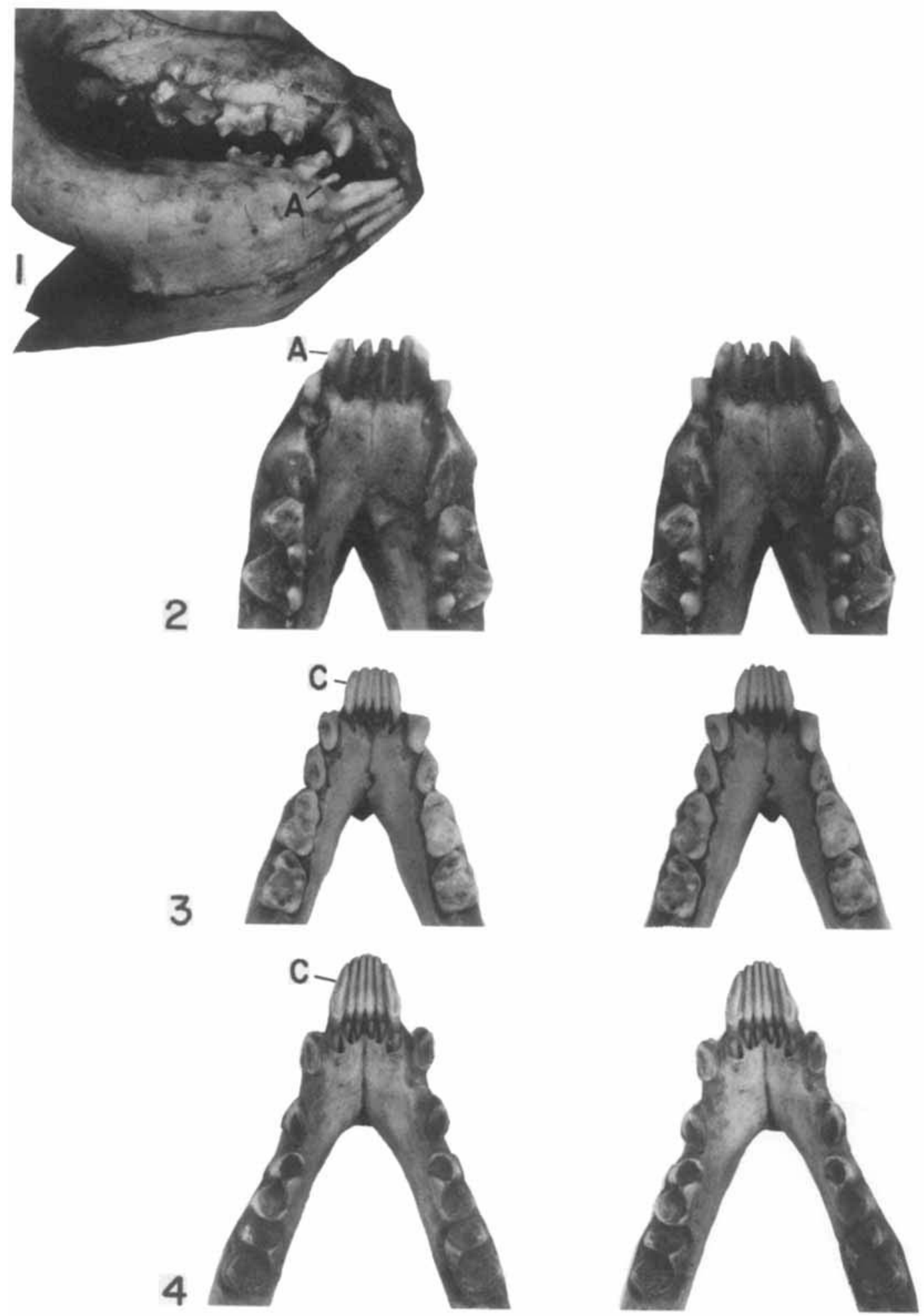